\title{
Gastrointestinal Manifestations of Mature B Cell Neoplasms: Single Center Experiences from the Collective Perspective of Hematology and Pathology
}

Ufuk Demirci ( $\square$ ufukdemirci3232@gmail.com )

Trakya University Faculty of Medicine: Trakya Universitesi Tip Fakultesi https://orcid.org/0000-00016923-1470

\section{Busem Binboğa Kurt}

Trakya University: Trakya Universitesi

\section{Seda Karaman Gülsaran}

Trakya University: Trakya Universitesi

\section{Volkan Baş}

Trakya University: Trakya Universitesi

\section{Tuğcan Alp Kırkızlar}

Trakya University Faculty of Medicine: Trakya Universitesi Tip Fakultesi

\section{Hakkı Onur Kırkızlar}

Trakya University: Trakya Universitesi

\section{Elif Gülsüm Ümit}

Trakya University: Trakya Universitesi

\section{Fulya Öz Puyan}

Trakya University: Trakya Universitesi

\section{Ahmet Muzaffer Demir}

Trakya University: Trakya Universitesi

\section{Research Article}

Keywords: non-Hodgkin lymphomas, B cell neoplasm, Gastrointestinal lymphomas, Pathology

Posted Date: December 8th, 2021

DOI: https://doi.org/10.21203/rs.3.rs-1146269/v1

License: (c) (1) This work is licensed under a Creative Commons Attribution 4.0 International License. Read Full License 


\section{Abstract}

Introduction: Hematological malignancies are frequently affecting the gastrointestinal (GI) tract, either by secondary extra nodal or extramedullary extension to the $\mathrm{Gl}$ tract, or as a primary process arising in the $\mathrm{Gl}$ tract. Gastrointestinal non-Hodgkin lymphomas ( $\mathrm{gNHL}$ ) appear less than other solid organ tumours in the GI tract. Therefore, in the absence of nodal or extra nodal involvement in imaging methods, there may be difficulties in diagnosis. Haematologists provide more important support by pathologists in terms of diagnosis than imaging methods.

Methods: We retrospectively investigated all B-cell lymphoma patients diagnosed in our clinic between 01.01.2015- 01.01.2021. After that, patients not diagnosed by gastrointestinal system sampling were excluded from the study. Demographic data of these patients were obtained from the hospital information system and outpatient clinic files. Slides of these patients were obtained from pathology archive and re-evaluated under light microscope by two pathologists. All cases were diagnosed according to revised World Health Organization (WHO) 2017 classification.

Results: 55 patients were diagnosed with B-cell lymphoma by sampling by endoscopy or colonoscopy. 40 of the patients were diagnosed with Diffuse Large B Cell Lymphoma (DLBCL), 10 with Marginal Zone Lymphoma (MZL), 2 with Mantle Cell Lymphoma (MCL), 2 patients with Burkitt Lymphoma (BL) and 1 patient with Lymphoplasmacytic Lymphoma (LPL).

Conclusion: Like the literature, the frequency of DLBCL was the highest in patients diagnosed with $\mathrm{GI}$ tract in our study. The second most common B-cell lymphoma was MALToma. Although MCL is with a high frequency of GI involvement, there were few patients diagnosed with GI involvement. The reason for this was that the patients were diagnosed with nodal involvement rather than GI sampling.

\section{Introduction}

Hematological malignancies are classified under a wide range and consist of lymphoproliferative and myeloproliferative malignancies. These malignancies frequently affect the gastrointestinal (GI) tract, either by secondary extra nodal or extramedullary extension to the $\mathrm{Gl}$ tract, or as a primary process arising in the GI tract. In fact, GI tract is the most common extra nodal site involved in non-Hodgkin lymphoma $(\mathrm{NHL})$. Although primary gastrointestinal non-Hodgkin lymphomas are rare among other $\mathrm{GI}$ malignancies (1-4\%), it is an important entity that affects approximately $10-15 \%$ of all NHL patients and $30-40 \%$ of extra nodal NHL patients $[1,2]$. Secondary lymphomatous dissemination to the $\mathrm{Gl}$ tract is even more frequent and is found in up to $50 \%$ of lymphomas at autopsy [3].

Gastrointestinal non-Hodgkin lymphomas ( $\mathrm{gNHL}$ ) appear less than other solid organ tumours in the $\mathrm{GI}$ tract. Therefore, in the absence of nodal or extra nodal involvement in imaging methods, there may be difficulties in diagnosis. Hematologists provide more important support by pathologists in terms of diagnosis than imaging methods. Therefore, providing detailed information to the pathologists about the 
patient's clinic and imaging results is of great importance for diagnosis. The clinician should establish this information network well.

It is important as a pathologist to evaluate GI biopsies in correlation with clinical, endoscopic, and radiological findings (Computed tomography (CT), Endoscopy-Colonoscopy, Endoscopic Ultrasonography (EUS), etc.). If B symptoms (fever, night sweats and weight loss) are present, lymphoma suspicion arises. However typical site related gastrointestinal symptoms such as dyspepsia, abdominal pain, nausea and vomiting may be the only presentation. In some patients' GI lymphoma may present incidentally [4]. Symptomatic patients may not have typical correlated endoscopic features [5]. Although exophytic, ulcerative or hypertrophic lesions are common, the only endoscopic findings may be inflammation-like patterns such as petechia or normal/hyperaemic mucosa $[5,6]$. After gathering the information, to distinguish -especially low grade- lymphomas from inflammatory lesions is the initial approach of a pathologist to avoid delayed diagnosis. Dense lymphoid infiltrates with numerous lymphoepithelial lesions, moderate cytological atypia or Dutcher bodies are considered to be alarming for lymphoma diagnosis alongside with features such as muscularis mucosae invasion or ulceration [7]. After the initial approach, subtyping is essential in terms of treatment decision and prognosis ,[8].

Together with the experiences of our clinic, we aimed to examine our B-cell gNHL patients and to share the hematologists and pathologists approaches of these patients with this information. In addition, we planned to discuss the management process of these patients from diagnosis to treatment in the light of current literature.

\section{Material - Methods}

We retrospectively investigated all B-cell lymphoma patients diagnosed in our clinic between 01.01.201501.01.2021. After that, patients not diagnosed by gastrointestinal system sampling were excluded from the study. Demographic data of these patients were obtained from the hospital information system and outpatient clinic files. Also, we examined the response rates of the patients after treatment and their follow-up for the gastrointestinal system.

Slides of these patients were obtained from pathology archive and re-evaluated under light microscope by two pathologists. All cases were diagnosed according to revised World Health Organization (WHO) 2017 classification. Immunohistochemical results were obtained from the pathology reports and controlled via checking previously stained slides. Cell of origin (COO) was assessed according to the Hans criteria. According to Hans criteria cases were considered positive if $30 \%$ or more of the tumour cells were stained with the antibody. Hans algorithm was made up of three markers (CD10 antibody for Germinal center (GC) origin, BCL6 antibody for GC and non GC origin, MUM1 antibody for post GC origin). Based on combination of the three markers, Hans algorithm could divide DLBCL into two subtypes: GC and non-GC.

The study was conducted in accordance with the Declaration of Helsinki Ethical Principles for Medical Research. All Patients gave and signed informed consent. This study was approved by Trakya University 
ethical committee (TÜTF-BAEK 2021/234).

Statistical analyses were performed using SPSS PC Ver.22 (IBM @ SPSS Inc. USA). Descriptive statistics were given as number, percentage, and arithmetic mean \pm standard deviation (minimum -maximum). A two-sided $p$ value less than 0.05 considered significant. Overall survival (OS) was defined as time from diagnosis of lymphoma to death. To evaluate overall survival; Kaplan-Meier overall survival (OS) estimates were calculated. Log rank test and Cox regression analysis were performed to evaluate estimate hazard ratios (HR) and 95\% Confidence Intervals (Cl).

\section{Results}

55 patients were diagnosed with B-cell lymphoma by sampling by endoscopy or colonoscopy. 40 of the patients were diagnosed with Diffuse Large B Cell Lymphoma (DLBCL), 10 with Marginal Zone Lymphoma (MZL), 2 with Mantle Cell Lymphoma (MCL), 2 patients with Burkitt Lymphoma (BL) and 1 patient with Lymphoplasmacytic Lymphoma (LPL) (Figure-1) / (Table -1).

40 of 55 patients who were diagnosed with B Cell NHL with gastrointestinal system involvement had a diagnosis of Diffuse Large B Cell Lymphoma. The mean age of DLBCL patients was 65 and 18 patients were female. The majority of DLBCL patients were diagnosed from stomach biopsy (75\%). 4 patients were diagnosed from the colon, 3 from the oropharyngeal area, 2 from the ileum and 1 from the oesophagus. Nine of the patients were asymptomatic at diagnosis, 19 patients had abdominal pain, 17 patients had weight loss, 11 patients had vomiting, and 2 patients had dysphagia. One patient was presented with perforation. Eighteen of the patients expressed CD10, BCL6 immunoreactivity and were diagnosed as germinal centre origin immunophenotype according to Hans algorithm. Eleven patients were double / triple expressor (C-MYC and BCL2 or c-MYC, BCL2 and BCL6 immunoexpression). When evaluated in terms of prognostic factors, we found that 21 patients had $B$ symptom and 31 patients were diagnosed with high Lactate Dehydrogenase (LDH), 20 patients had R-IPI score $>2$ and 26 patients had NCCN-IPI> 3. It was observed that 17 patients died and 7 of the patients who died could not or did not want to receive treatment. Besides, 10 of the patients died in the first month. R-CHOP chemotherapy was given to all patients who received treatment. The mean survival of the patients who received treatment was 39.5 months. It was seen that only 10 patients underwent GI endoscopy after treatment. Involvement in a different area of the ileum was observed in 1 patient. No other patient had GI involvement in posttreatment setting. Radiological involvement was not detected in other alive patients.

Ten patients were diagnosed with MZL (MALTOMA) and 6 patients were male of them. Average age was 67.4 years. Five patients received $\mathrm{H}$. Pylori therapy. Also, 5 patients received systemic therapy (4 Patients R-CHOP, 1 Patient Rituximab) due to their stages. Control endoscopy was performed for all patients during their follow-up. It was observed that 2 patients relapsed after systemic therapy. The mean followup of all patients was 47.9 months. No relapse was found in patients receiving H. Pylori therapy. Followup of all patients continues. 
Two patients were diagnosed with MCL. One patient was diagnosed from the colon, one from the ileum. Both patients were male. The average age of the patients was 63.5 years old. One of the patients underwent autologous stem cell transplant (ASCT) after high dose therapy. Relapse disease was detected in the patient during the first control in the same location after ASCT. Endoscopic control was not performed in the other patient, control was done with PET / CT. There was no relapse. Both patients are alive, and the median survival was 21.5 months.

Two patients were diagnosed with Burkitt's Lymphoma. All of them diagnosed from the colon. Mean age was 46 years and both patients were male. After high dose therapy, 1 patient died after the first course due to sepsis, and the other patient was referred to ASCT because of complete response in control PET / CT. The diagnosis of LPL in 1 patient was made by colonoscopy. The 74-year-old male patient has been followed up for 24 months.

\section{Discussion}

Gastric NHLs, which constitute 1-4\% of all GI malignancies, are seen most frequently in the stomach (60$75 \%$ of all cases), then in the small intestine and ileocecal area. Histopathological findings in GI tract reveal indolent as well as aggressive lymphomas, which may consist of mature $B, T$ or NK cells. Intestinal B-cell lymphomas are more frequent than T-cell lymphomas $(6: 1)[2,3,9]$. DLBCL and MZL's are the most frequently encountered by the clinician.

Observing conditions of $\mathrm{Gl}$ tract from top to bottom, it is seen that there is a wide range of symptoms of these patients. In upper $\mathrm{Gl}$ tract involvement, patients may present with symptoms such as dysphagia and hoarseness. Symptoms such as abdominal pain, weight loss, nausea and vomiting can be observed in gastric involvement, which constitutes $60-75 \%$ of patients with gNHL. Patients with small intestine (\%20) and colon (\%6-12) involvement may present with clinical symptoms secondary to obstruction, weight loss and bleeding $[3,9]$.

Computed tomography and magnetic resonance imaging are valuable in diagnosis for sites of lymphoma involvement other than GI tract. Endoscopic ultrasonography is more valuable in $\mathrm{Gl}$ tract especially in case of mucosal involvement. It can also be used in the follow-up of the disease after treatment. 18F-fluorodeoxyglucose positron emission tomography (FDG-PET) is frequently used in diagnosis and follow-up. However, histopathological evaluation is recommended for mucosal evaluation after treatment, especially in patients diagnosed from the stomach $[2,9]$.

Main histopathologic groups of gastrointestinal lymphomas are mature B cell lymphomas, T cell lymphomas and NK/T cell lymphomas. Since the most common group is mature B cell, MALT lymphoma and DLBCL substitutes most of the cases. Other B cell lymphomas are follicular lymphoma, BL, MCL and rarely; lymphomatoid granulomatosis, LPL, EBV positive DLBCL, high grade B cell lymphoma, small lymphocytic lymphoma, ALK positive large B cell lymphoma, plasmablastic lymphoma and extramedullary plasmacytoma [10]. 
Diffuse Large B-Cell Lymphoma is the most common among gNHL. It accounts for $38-57 \%$ of $\mathrm{gNHL}$ patients. When all GI Lymphomas are evaluated, it was noticed that $40-78 \%$ are DLBCL. Frequently, DLBCL is manifested as a mass-forming lesion or less likely as an infiltrative lesion [11]. There is a tendency to invasion nearby structures, which can cause mucosal ulceration and perforation. GI obstruction is less common. However, if the muscularis propria is invasion in small bowel involvement, aneurysmal dilation can be seen as a result of the destruction of the intramural autonomic nerve plexus. There is often accompanying intraabdominal lymph node involvement. The classical R-CHOP regimen has been used in treatment for a long time $[9,10,11,12]$.

Consistent with the literature, most of our patients were diagnosed with DLBCL (73\%) and were diagnosed with gastric biopsy. Most of the patients (77.5\%) had gastrointestinal system-related symptoms at the time of diagnosis, only 9 patients were asymptomatic. This should be interpreted as a result of how much the clinician should attach importance to the anamnesis from the diagnosis stage of the patients. In the follow-ups, $42 \%$ of the patients were exitus. It should be emphasized that rapid and careful management is required after diagnosis, since a significant portion of these patients $(58.8 \%)$ die within the first month after diagnosis.

From pathologist perspective: Diffuse large B cell lymphoma consists of three main morphological variants: centroblastic, immunoblastic and anaplastic. Centroblasts are medium-large sized cells with vesicular chromatin and 2-4 nucleoli based on nuclear membrane whereas immunoblasts have centrally located nucleolus (10). Anaplastic morphology should be distinguished from poorly differentiated carcinoma or melanoma. Neoplastic cells express pan-B cell markers such as CD20, CD19, CD79a and PAX5. Ki67 proliferation index is commonly $>40 \%$ (13). COO is another important subject in terms of treatment decision. Germinal center B cell subtype (GC) is originated from germinal cells whereas activated $B$ cell subtype $(A B C)$ is derived from germinal center exit/post germinal center. Hans et al. developed an immunohistochemistry-based algorithm which has high concordance with gene expression profiling to classify cell of origin (14). Accordingly, CD10, BCL6 and IRF/MUM1 are considered positive if $\geq 30 \%$ cells are stained. CD10+ or BCL6+ MUM1- refers to GC subtype, whereas BCL6- or BCL6+ MUM1+ refers to ABC subtype. Meyer et al [15] included GCET1 and LMO2 as GC markers and FOXP1 as ABC marker. HGAL/GCET2 is also considered to be a GC marker [16]. CD30 positivity may be observed in 10$20 \%$ patients with DLBCL [17]. However additional presence of EBV cases should be diagnosed as EBV positive DLBCL. DLBCL lymphoma may also express MYC and BCL2 by immunohistochemistry which is called double expressor. However, this do not indicate double hit status of translocation and should be distinguished from high grade B cell lymphomas [18] (Figure-2).

Marginal zone lymphoma is the 2 nd most common gNHL with a frequency of $23-48 \%$. Half of the patients have gastric involvement. H. pylori is an important risk factor and $90 \%$ of the patients with MALT lymphoma are positive, and antibacterial therapy is sufficient in the majority of cases. IPSID, which is called immunoproliferative small intestinal disease or alpha heavy chain disease, is seen in young patients with duodenum involvement and is common in the Middle East. This disease, also called Mediterranean lymphoma, is caused by C. jejuni. FDG-PET or CT may be insufficient in MZL patients with 
an indolent lymphoma. Endoscopic methods with histopathological diagnosis are more valuable. In addition to watch and wait, in patients in need of treatment, regimens such as Rituximab single, R-CVP, RCHOP are used in treatment $[1,9,11,19]$.

MALT lymphoma (18\%) was the second most common B lymphoma group in our patients, similar to the literature. Our patients were also followed up endoscopically because of the possibility of diagnostic sampling in MALT lymphoma patients with indolent course and because endoscopic methods are better for evaluation after treatment. Relapse was detected in $20 \%$ of the patients during endoscopic follow-up.

From pathologist perspective: MALT lymphoma which exhibits t[11;18] [q21;q21] most frequently [20], consists of small lymphoid cells with irregular nucleus and hyperchromasia. Since there is no specific immunohistochemical profile and it is mostly a ruling out diagnosis, a care must be taken to distinguish this tumour from benign reactive lymphoid tissue. Lymphoma cells proliferate in a marginal zone pattern and around reactive follicles which then form confluent dense areas that leads to follicle replacement [10]. Lymphoepithelial lesions (aggregates of $\geq 3$ marginal zone cells with distortion or destruction of the epithelium) and deeper infiltration should be examined carefully. CD20 positive cells may have plasmacytic differentiation that can be highlighted by kappa and lambda immunostaining [21]. CD21 and CD23 may be helpful to highlight the dispersed dendritic cell network. CD5 positivity may be observed in rare cases [22] (Figure-3).

Mantle Cell Lymphoma accounts for $5-13 \%$ of gNHL patients. It is known that extra nodal involvement is common in $\mathrm{MCL}$ and patients have approximately $90 \% \mathrm{Gl}$ involvement. Routine screening is not recommended [23]. Most patients are diagnosed with non-GI tract involvement. It is detected as small mucosal polyps, often in the small intestine or colon. We think that the number of patients diagnosed with gastrointestinal sampling is low, since we do not routinely take endoscopic sampling from all MCL patients at the time of diagnosis.

From pathologist perspective: Mantle cell lymphoma consists of small to medium sized monomorphic cell population which exhibits different patterns which may cause diagnostic difficulties: nodular, diffuse, mantle zone and follicular [10]. Lymphoma may occur as multiple mucosal polyps and called multiple lymphomatous polyposis [24]. MCL is characterized by the translocation $t[11 ; 14]$ [q13;q32] and leads Cyclin D1 overexpression [25]. Main immunohistochemical features are CD5 positivity whereas BCL6, CD10 and CD23 negativity (may be weakly positive). Cyclin D1 is expressed in most of the cases (CD5 negative cases included) and SOX 11 is highly sensitive even in Cyclin D1 negative cases [26]. DLBCL, especially those who show CD 5 positivity should be separated from blastoid variant of MCL. Cyclin D1 and SOX11 are helpful in this aspect (Figure- 4).

Follicular Lymphoma (FL) is the most common lymphoma among indolent lymphomas. $\mathrm{FL}$ is the most common among nodal lymphomas after DLBCL. Extra nodal involvement is not common in patients. GI is seen in $5-12 \%[11,18]$. 
From pathologist perspective: Follicular lymphoma is a relatively rare extra nodal lymphoma involving gastrointestinal tract which usually effects primarily duodenum (26) which presents as multiple small polyps and subtyped as duodenal type FL with a good prognosis $(10)$. The translocation $(14 ; 18)$ which involves BCL2 locus is observed mostly of these cases [28]. Follicular lymphoma subtypes including in situ follicular neoplasia is characterized by CD10 and BCL2 positivity of the effected germinal centers. This panel is important to differentiate from reactive follicles. Ki67 proliferation index is usually low and restricted peripheral dendritic cells of the follicle may be highlighted by CD21 [29].

Burkitt's Lymphoma is an aggressive B lymphoma that is less common in adult lymphomas and constitutes $5 \%$ of gNHLs. The sporadic subtype is more common with $\mathrm{Gl}$ involvement. It is frequently encountered with intraabdominal bulky involvement. High lactate dehydrogenase and tumor lysis are laboratory changes that we may encounter in diagnosis. The c-MYC rearrangement is non-specific but often found. ASCT should be performed after a more aggressive treatment (CODOX-M/IVAC, RHyperCVAD, CALGB regimen, etc.) [11, 30].

From pathologist perspective: Burkitt lymphoma is an aggressive tumor mostly seen in terminal ileum of the gastrointestinal tract [31]. Cells of Burkitt lymphoma are usually basophilic and medium sized with angulated borders. Chromatin is usually clumped with multiple nuclei. Tumors have high proliferation with numerous mitotic figures and apoptosis. Starry sky appearance is due to tingible body macrophages [10]. CD20, CD19 and CD79a are positive as well as germinal center markers such as CD10 and BCL6. Ki67 proliferation index is nearly \%100 and there is MYC overexpression. Aberrant BCL2 expression may be observed however high expressions should be differentiated from high grade B cell lymphomas [32]. DLBCL is another differential diagnosis especially if it is characterized by medium sized cells. However, BL cells are more monomorphic and Ki67 proliferation index is higher than DLBCL while latter is approximately \%40-60 (Figure- 5).

\section{In summary:}

Like the literature, the frequency of DLBCL was the highest in patients diagnosed with GI tract in our study. The second most common B-cell lymphoma was MALToma. Although MCL is with a high frequency of $\mathrm{Gl}$ involvement, there were few patients diagnosed with $\mathrm{Gl}$ involvement. The reason for this was that the patients were diagnosed with nodal involvement rather than GI sampling. In addition, in our center, routine $\mathrm{Gl}$ tract scanning is not performed in MCL patients after diagnosis. Patients diagnosed with $\mathrm{BL}$ and $\mathrm{LPL}$ were rare, as expected. In accordance with the literature, the most common GI tract involvement was gastric mucosa (72\%). Less frequently, this was followed by colon $(12.7 \%)$ and ileum involvement.

We routinely use 18 FDG PET / CT method for evaluation before and after treatment in malignancies such as DLBCL, BL, MCL that can show a progressive course and have a high proliferation index. However, similar benefit in indolent malignancies may not be achieved due to the slow proliferation of the malignant tissues. Endoscopic methods and CT are used more frequently in the follow-up of these patients. Relapses were observed in 4 patients during follow-up by endoscopic method. Two patients had 
indolent disease. However, no relapse was detected during follow-up by PET / CT and endoscopic imaging was not required for these patients. We think that follow-up can be done by PET / CT. Although we frequently use 18 FDG PET / CT for follow-up, it is important to use endoscopic methods as they can be used for diagnostic purposes as well as imaging.

Because of its prevalence, clinicians often consider solid malignancies as initial differential diagnosis of the masses in Gl tract. Therefore, clinical findings of the patients are gaining great importance. In order to the diagnosis and the stage of the disease should be clear, the clinical information of the patients should be fully described by the clinician. The presence of B symptoms, splenomegaly, and lymph adenomegaly should be described, if any, their cytopenia's should be emphasized and shared with pathologists for accurate diagnosis and clinical management.

\section{Declarations}

Funding: This study has no funding

Conflicts of Interest: The authors have no conflict of interest to declare.

Ethics approval: Local Council of Ethics in 2021 by Trakya University (TÜTF-BAEK 2021/234)

Data will be available upon request, not in repository since it includes pathological data.

All authors have given consent to publication.

UD, BBK Constructing an idea / hypothesis for research

UD, BBK Planing methodology

UD, BBK, SKG, VB Collect samples from patients

UD, BBK Writing the article

HOK, EGÜ, FÖP, AMD Reviewing the article

All authors read and approved the manuscript

\section{References}

1) Bautista-Quach M. A, Ake C. D, Chen M, and Wang J. Gastrointestinal lymphomas: Morphology, immunophenotype and molecular features. J Gastrointest Oncol 2012;3(3):209-225

2) Ghimire P, Wu G, and Zhu L. Primary gastrointestinal lymphoma. World J Gastroenterol 2011 February 14; 17(6): 697-707 
3) Herrmann R, Panahon AM, Barcos MP, Walsh D, Stutzman L. Gastrointestinal involvement in nonHodgkin's lymphoma. Cancer 1980;46(1):215-222.

4) Koniaris LG, Drugas G, Katzman PJ, Salloum R. Management of gastrointestinal lymphoma. Journal of the American College of Surgeons. 2003;197(1):127-41.

5) Andriani A, Zullo A, Di Raimondo F, Patti C, Tedeschi L, Recine U, et al. Clinical and endoscopic presentation of primary gastric lymphoma: a multicentre study. Aliment Pharmacol Ther. 2006;23(6):7216.

6) Zullo A, Hassan C, Andriani A, Cristofari F, Cardinale V, Spinelli GP, et al. Primary low-grade and highgrade gastric MALT-lymphoma presentation. J Clin Gastroenterol. 2010;44(5):340-4.

7) Zukerberg LR, Ferry JA, Southern JF, Harris NL. Lymphoid infiltrates of the stomach. Evaluation of histologic criteria for the diagnosis of low-grade gastric lymphoma on endoscopic biopsy specimens. Am J Surg Pathol. 1990;14(12):1087-99.

8) Vetro C, Romano A, Amico I, Conticello C, Motta G, Figuera A, et al. Endoscopic features of gastrointestinal lymphomas: from diagnosis to follow-up. World J Gastroenterol. 2014;20(36):12993-3005.

9) Olszewska-Szopa M, and Wróbel T. Gastrointestinal non-Hodgkin lymphomas. Adv Clin Exp Med. 2019;28(8):1119-1124

10) Swerdlow SH CE, Harris NL, Jaffe ES, Pileri SA, Stein H. WHO classification of tumours of haematopoietic and lymphoid tissues-Revised 4th edition. World Health Organization Classification of Tumours. 2017.

11) Hanafy A.K, Morani A.C, Menias C.O, and et al. Hematologic malignancies of the gastrointestinal luminal tract. Abdominal Radiology (2020) 45:3007-3027

12) Pizzi $M$, Sabattini E, Parente $P$ and et al. Gastrointestinal lymphoproliferative lesions: a practical diagnostic approach. Pathologica. 2020 Sep; 112(3): 227-247.

13) Grogan TM, Lippman SM, Spier CM, Slymen DJ, Rybski JA, Rangel CS, et al. Independent prognostic significance of a nuclear proliferation antigen in diffuse large cell lymphomas as determined by the monoclonal antibody Ki-67. Blood. 1988;71(4):1157-60.

14) Hans $C P$, Weisenburger DD, Greiner TC, Gascoyne RD, Delabie J, Ott G, et al. Confirmation of the molecular classification of diffuse large B-cell lymphoma by immunohistochemistry using a tissue microarray. Blood. 2004;103(1):275-82.

15) Meyer PN, Fu K, Greiner TC, Smith LM, Delabie J, Gascoyne RD, et al. Immunohistochemical methods for predicting cell of origin and survival in patients with diffuse large B-cell lymphoma treated with rituximab. J Clin Oncol. 2011;29(2):200-7. 
16) Gualco G, Bacchi LM, Domeny-Duarte P, Natkunam Y, Bacchi CE. The contribution of HGAL/GCET2 in immunohistological algorithms: a comparative study in 424 cases of nodal diffuse large B-cell lymphoma. Mod Pathol. 2012;25(11):1439-45.

17) Hu S, Xu-Monette ZY, Balasubramanyam A, Manyam GC, Visco C, Tzankov A, et al. CD30 expression defines a novel subgroup of diffuse large B-cell lymphoma with favorable prognosis and distinct gene expression signature: a report from the International DLBCL Rituximab-CHOP Consortium Program Study. Blood. 2013;121(14):2715-24.

18) Swerdlow SH. Diagnosis of 'double hit' diffuse large B-cell lymphoma and B-cell lymphoma, unclassifiable, with features intermediate between DLBCL and Burkitt lymphoma: when and how, FISH versus IHC. Hematology Am Soc Hematol Educ Program. 2014;2014(1):90-9.

19) Thomas A.S, Schwartz M, and Quigley E. Gastrointestinal lymphoma: the new mimic. Shirwaikar Thomas A, et al. BMJ Open Gastro 2019;6:e000320.

20) Farinha P, Gascoyne RD. Molecular pathogenesis of mucosa-associated lymphoid tissue lymphoma. J Clin Oncol. 2005;23(26):6370-8.

21) Bautista-Quach MA, Ake CD, Chen M, Wang J. Gastrointestinal lymphomas: Morphology, immunophenotype and molecular features. Journal of gastrointestinal oncology. 2012;3(3):209-25.

22) Jaso J, Chen L, Li S, Lin P, Chen W, Miranda RN, et al. CD5-positive mucosa-associated lymphoid tissue (MALT) lymphoma: a clinicopathologic study of 14 cases. Hum Pathol. 2012;43(9):1436-43.

23) Jain P, and Wnag M. Mantle cell lymphoma: 2019 update on the diagnosis, pathogenesis, prognostication, and management. Am J Hematol. 2019; 94:710-725.

24) Nguyen V, Nguyen B, Petris GD, Nguyen C. Education and imaging. Gastrointestinal: gastrointestinal involvement of mantle cell lymphoma. J Gastroenterol Hepatol. 2012;27(3):617.

25) Salar A, Juanpere N, Bellosillo B, Domingo-Domenech E, Espinet B, Seoane A, et al. Gastrointestinal involvement in mantle cell lymphoma: a prospective clinic, endoscopic, and pathologic study. Am J Surg Pathol. 2006;30(10):1274-80.

26) Mozos A, Royo C, Hartmann E, De Jong D, Baró C, Valera A, et al. SoX11 expression is highly specific for mantle cell lymphoma and identifies the cyclin D1-negative subtype. Haematologica. 2009;94(11):1555-62.

27) Misdraji J, Harris NL, Hasserjian RP, Lauwers GY, Ferry JA. Primary follicular lymphoma of the gastrointestinal tract. Am J Surg Pathol. 2011;35(9):1255-63.

28) Leich E, Salaverria I, Bea S, Zettl A, Wright G, Moreno V, et al. Follicular lymphomas with and without translocation $t(14 ; 18)$ differ in gene expression profiles and genetic alterations. Blood. 2009;114(4):826- 
29) Takata K, Sato Y, Nakamura N, Tokunaka M, Miki Y, Yukie Kikuti Y, et al. Duodenal follicular lymphoma lacks AID but expresses BACH2 and has memory B-cell characteristics. Mod Pathol. 2013;26(1):22-31.

30) Jacobson C and LaCasce A. How I treat Burkitt lymphoma in adults. Blood (2014) 124 (19): 29132920.

31) Choi SY, Kim SJ, Kim WS, Kim K, Ko YH. Aggressive B cell lymphomas of the gastrointestinal tract: clinicopathologic and genetic analysis. Virchows Arch. 2011;459(5):495-502.

32) Haralambieva E, Boerma EJ, van Imhoff GW, Rosati S, Schuuring E, Müller-Hermelink HK, et al. Clinical, immunophenotypic, and genetic analysis of adult lymphomas with morphologic features of Burkitt lymphoma. Am J Surg Pathol. 2005;29(8):1086-94.

\section{Tables}


Table -1: Demographic characteristics of GI Non-Hodgkin lymphoma patients

No. of cases N: 55 (\%)

\section{Gender Male/Female}

$37 / 18(67 / 33)$

Age

64 years $(21-92)$

\section{Localization}

Oropharyngeal Area

$3(5,4)$

Esophagus

$1(1,8)$

Gastric

$40(72,7)$

Ileum

$3(5,4)$

Colon

$8(14,5)$

\section{Histological Type}

DLBCL

$40(72,7)$

MZL

10 (18)

MCL

$2(3,6)$

$B L$

$2(3,6)$

LPL

$1(1,8)$

Isolated GI Involvement

$20 / 55(36,3)$

DLBCL

$15 / 40(37,5)$

MZL

$5 / 10(50)$

MCL

$B L$

LPL

\section{Clinical Symptoms or Signs of Patients Before Diagnosis}

Abdominal Pain

$24(43,6)$

Weight loss

$19(34,5)$

Vomiting

$11(20)$

Dysphagia

$2(3,6)$

Perforation

$1(1,8)$

Asymptomatic

$12(21,8)$ 
- DLBCL: Diffuse large B cell lymphoma, MCL: Mantle cell lymphoma, MZL: Marginal zone lymphoma, BL: Burkitt lymphoma, LPL: Lymphoplasmacytic lymphoma

\section{Figures}
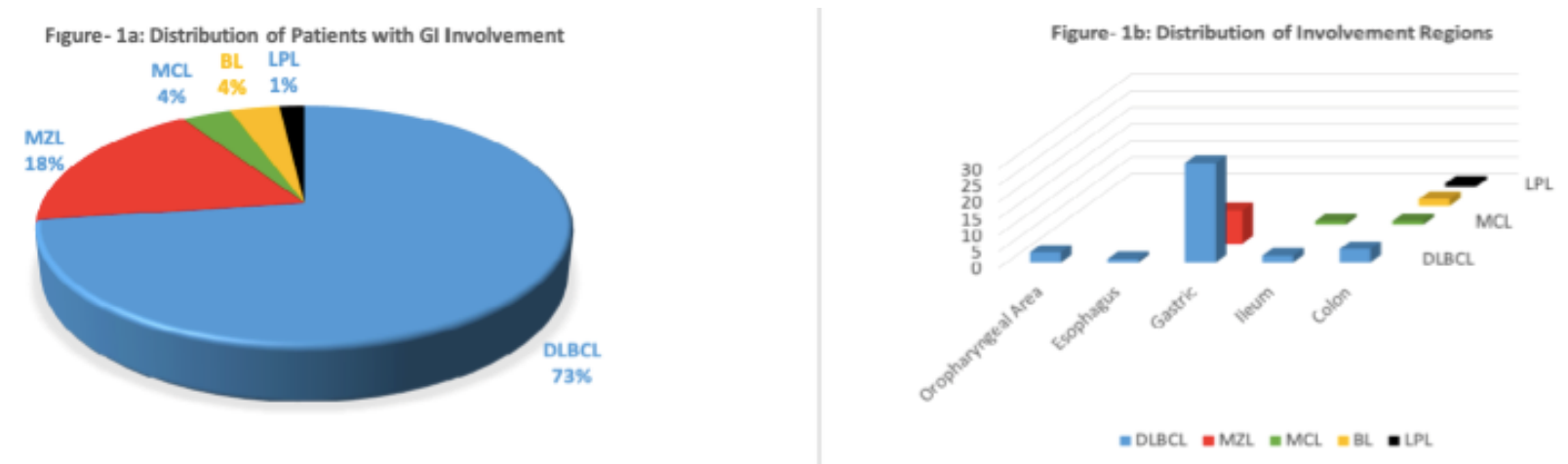

\section{Figure 1}

Diagnosis and involvement distributions of B Lymphoma patients

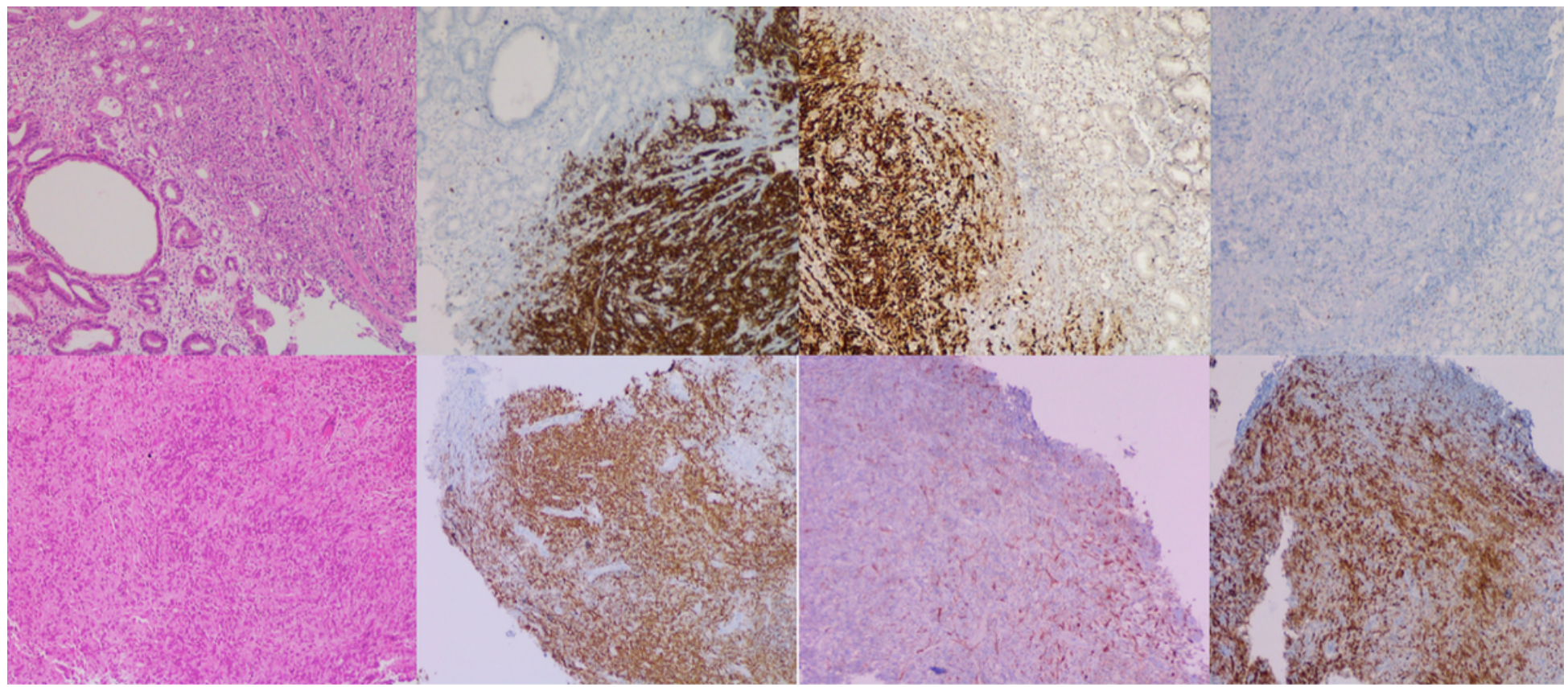

\section{Figure 2}

Diffuse large B cell lymphoma microphotographs (x100); Germinal center B cell: Atypical lymphocyte infiltration involving the lamina propria and submucosa of the stomach antrum, with dense crush artifact progressing between glands (A, H\&E), CD20 (B) and bcl-6 positive (C), MUM1 negative (D). Activated B cell: Atypical lymphocytes with intense crush artifact infiltrated the submucosa of the antrum (E, H\&E), CD20 diffuse positive (F) while CD10 is only positive in stromal cells $(\mathrm{G})$ and MUM1 is strongly positive in atypical lymphocytes $(H)$. 


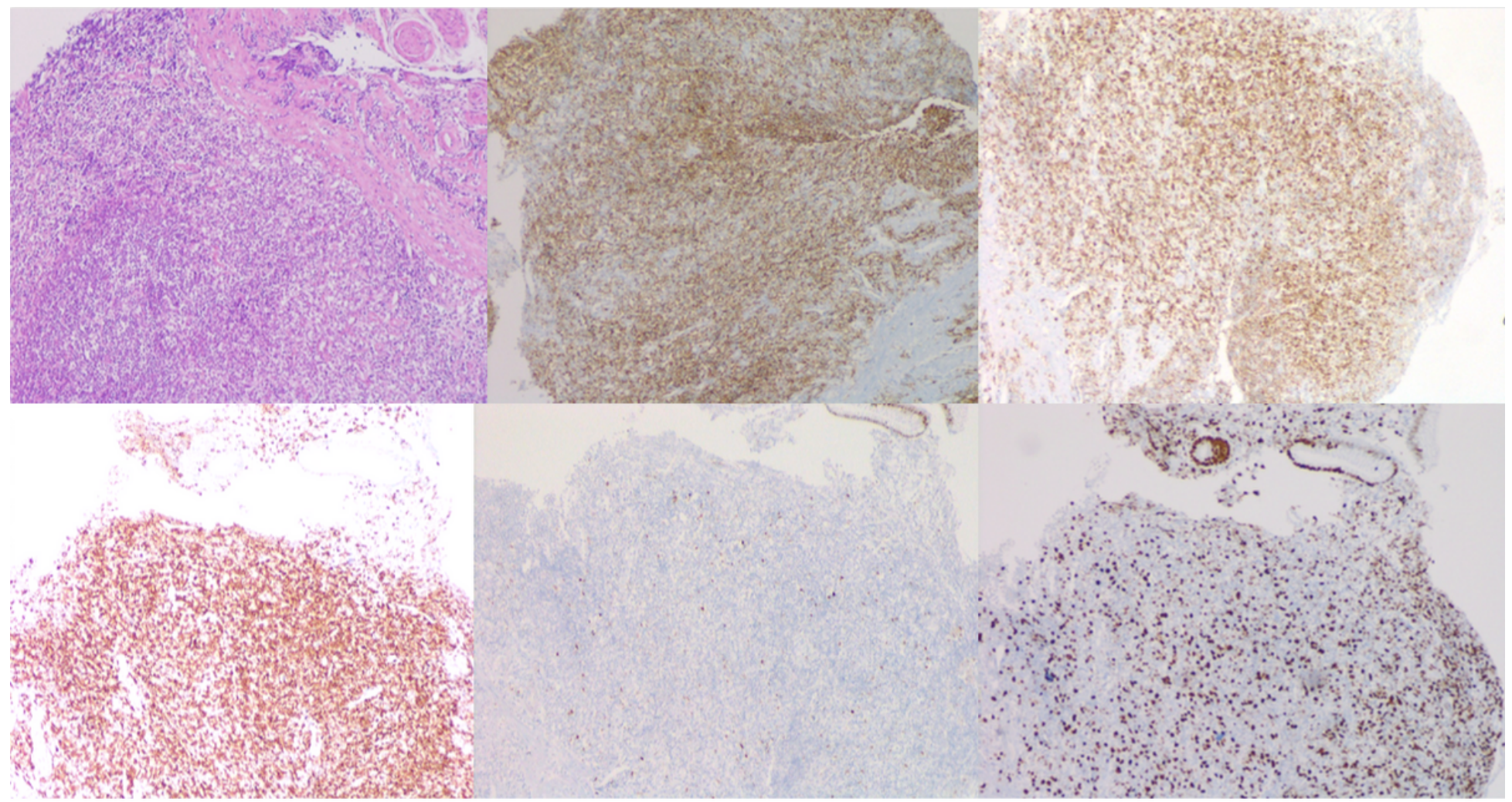

\section{Figure 3}

Mantle cell lymphoma microphotographs (x100); Infiltration of medium-sized monotone lymphocytes showing infiltration between antral mucosal glands and towards the submucosal area (A, H\&E), CD20 (B) and CD5 (C) diffuse positive, strong immunoreaction of CyclinD1 (D)

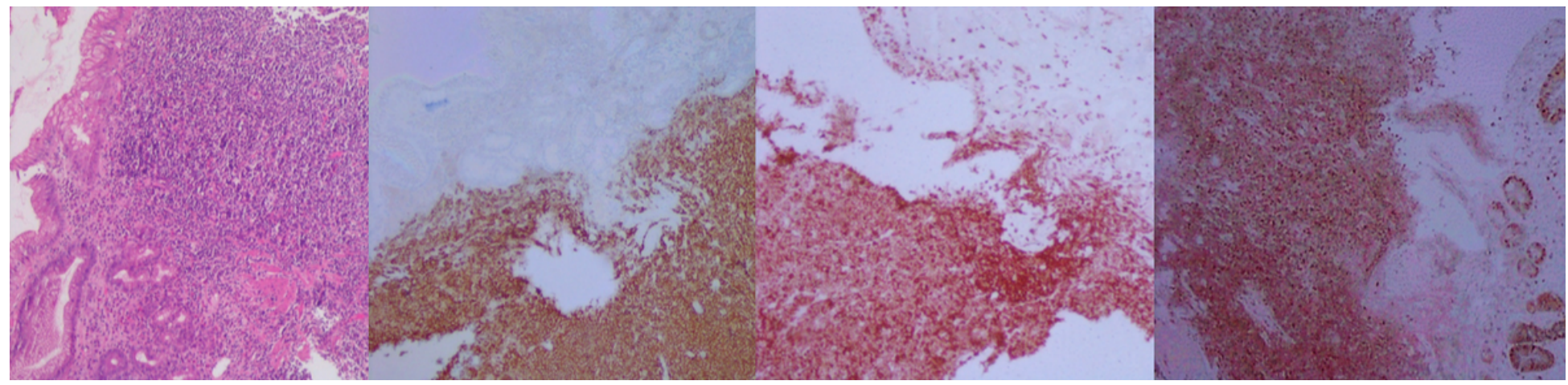

\section{Figure 4}

Extranodal marginal zone lymphoma of mucosa associated lymphoid tissue (MALT lymphoma) microphotographs (x100); Lymphoid proliferation with gland destruction, passing through the muscularis mucosa and spreading to the submucosal area. Secondary follicles accompany this proliferation $(A$, H\&E), atypical lymphocytes are CD20 positive (B), CD5 (C) and CD3 negative (D), CyclinD1 is also negative while Ki67 proliferation index is $\% 20-30$. 


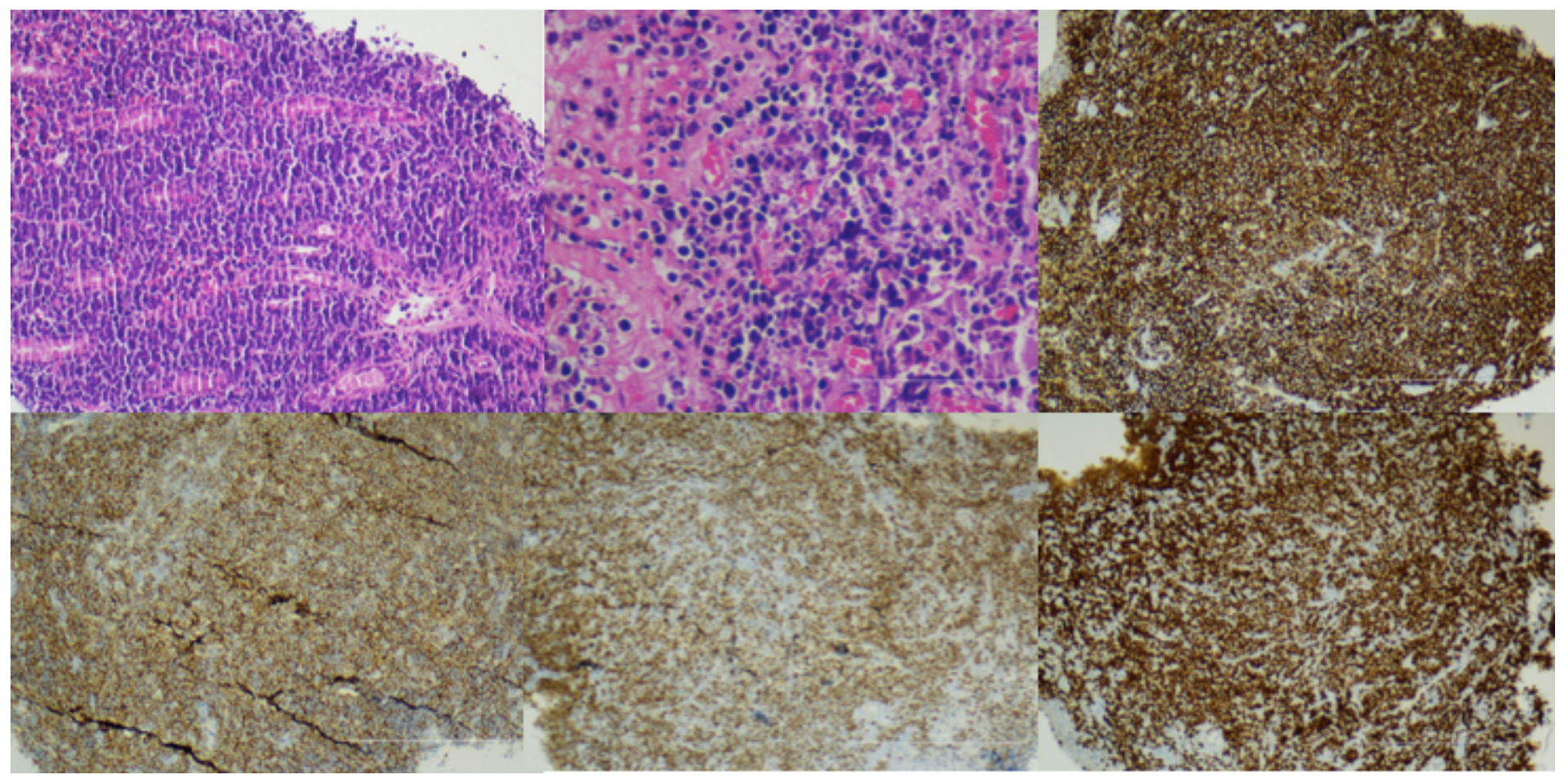

\section{Figure 5}

Burkitt lymphoma microphotographs: Dense atypical lymphoid proliferation in lamina propria of the stomach antrum $(A, H \& E, x 100)$. Cells are monomorphic with coarse chromatin and mitotically active (B, $H \& E, x 400) . C D 20$ (C) and CD10 (D) are diffuse positive, c-myc \%90 (E), ki67 proliferation index is \%100 $(\mathrm{F})$ 